\title{
Development of a monitoring network for surface subsidence at New Gold's New Afton block cave operation
}

MA Clayton BGC Engineering Inc., Canada

M Dugie BGC Engineering Inc., Canada

A LeRiche BGC Engineering Inc., Canada

C McKane BGC Engineering Inc., Canada

AGL Davies New Gold Inc., Canada

\begin{abstract}
New Gold's New Afton mine is a six million tonne per year operating mine located $8 \mathrm{~km}$ southwest of Kamloops, British Columbia, Canada. The current mining lift is approximately $600 \mathrm{~m}$ below ground, partially beneath the historical Afton pit. The subsidence zone at New Afton has developed asymmetrically and has deviated from the initial feasibility study modelling estimates. The growth of the subsidence zone extents is now being monitored in consideration of the mine's surface infrastructure.

The subsidence monitoring system at New Afton has been developed in phases in response to project needs. Initially, monitoring was setup to track the predicted cave growth and surface deformation near the crater. The monitoring network was expanded to areas away from the crater using additional instruments of various types. An automated data collection and retrieval system was implemented, with existing electrical instruments retrofitted to collect and transmit data automatically to the mine's database. Drilling completed to install these instruments allowed collection of new subsurface information used to refine the geological model, thus improving the mine's understanding of subsidence progression. In addition to providing information necessary for day-to-day mine operations, data collected from this monitoring system allow for refinement of predictions of future subsidence. The different data types each come with limitations and interpretation challenges. This paper discusses the development of the monitoring network, along with instrument selection criteria and performance information for New Afton.
\end{abstract}

Keywords: monitoring, instrumentation, subsidence

\section{Introduction}

The New Afton mine is an active block cave operated by New Gold in British Columbia, Canada. The site is located $8 \mathrm{~km}$ southwest of Kamloops and was historically operated as an open pit. Underground mining began in 2012, in what is referred to as the West Cave of Lift 1, located approximately $600 \mathrm{~m}$ below ground surface.

Block cave mining often breaks through to the ground surface, generating a caved zone (or crater) above the cave. Adjacent to the caved zone is a fractured zone, where large discrete tension cracks occur in the ground surface; this may also be referred to as the discontinuous subsidence zone. Outside the fractured zone is a subsidence zone where ground settlement is expected to be diffuse and only minor surface cracking may be present. A schematic illustrating the generalised deformation zones caused by block cave mining is shown in Figure 1.

A common challenge in the planning stage of block cave mines is making accurate predictions of the extent and magnitude of cave-induced subsidence. These predictions are important to allow for planning of surface infrastructure for operations, and to estimate the long-term impacts of mining. These pre-mining predictions are based on data-limited geological and geotechnical models of the orebody and host rock, and the proposed mine geometry and production schedule that is subject to change over the mine life. 
Empirical relationships or numerical modelling may be used depending on the stage of study and amount of data available.

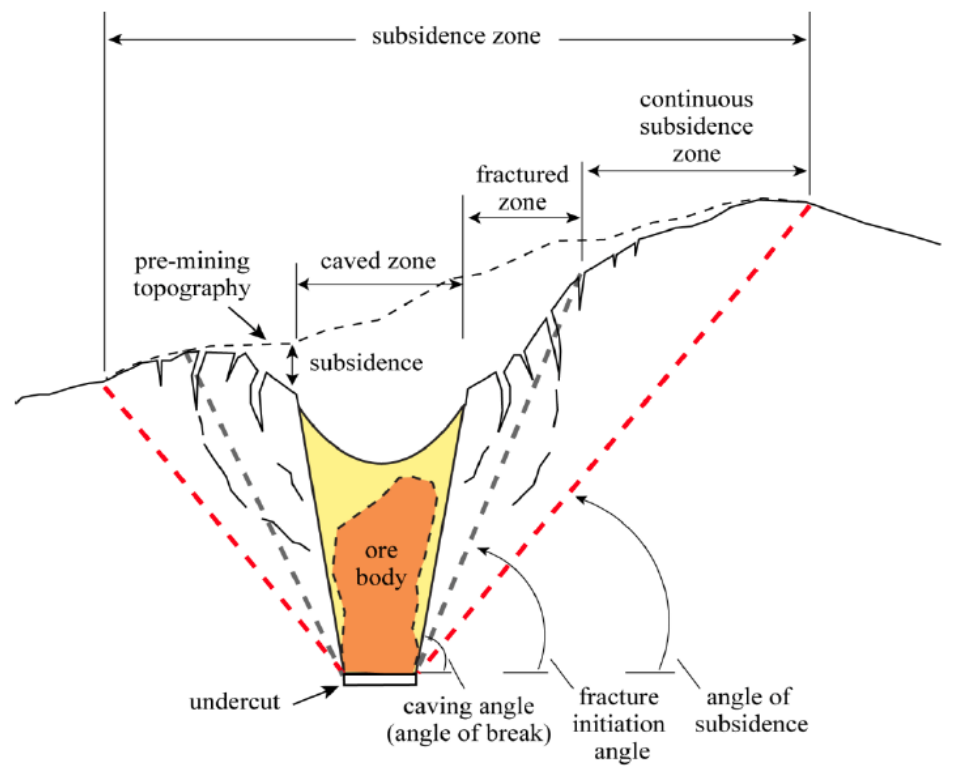

Figure 1 Schematic deformation zones caused by block cave mining (Woo 2011, adapted from van As et al. 2003)

Surface subsidence monitoring is typical for operating block cave mines. Understanding the cave-induced subsidence behaviour allows for better prediction of future ground behaviour (especially important for potential mine expansions), insight into the underground cave development, and safe working conditions. Monitoring the initiation and progression of subsidence also allows for early identification of deviations from anticipated ground behaviour and calibration of predictive models. There are a number of monitoring techniques that can be utilised for block cave-induced subsidence, ranging from simple survey points through to high-tech subsurface deformation sensors and high-resolution remote sensing. The scope of the monitoring network should be matched to specific project risks associated with subsidence.

This paper will discuss the design and evolution of the monitoring system for the New Afton mine. The site of the New Afton mine was previously the Afton mine, an open pit operation that generated surface waste rock dumps and a tailings storage facility. The location of the mine infrastructure and the size of the mineral tenure have left little additional space for new infrastructure. Siting of the required surface facilities for the new operation relied on feasibility-level subsidence predictions.

Bedrock is primarily Nicola Group volcanic and sedimentary rocks that were intruded by the Iron Mask diorite batholith complex that hosts the orebody (Logan \& Mihalynuk 2005; Lipske \& Wade 2014). The Ashcroft and Kamloops groups unconformably overlie the Nicola and Iron Mask units. The Nicola Group consists of a volcanic fragmental breccia, and picrite basalt; the picrite unit has a relatively lower strength and rock mass quality. The area is cut by regional-scale north-northeast trending and steep to moderately dipping fault zones. There are two main surficial units above the bedrock in the New Afton subsidence zone; glacial sediments that range in thickness from less than $5 \mathrm{~m}$ to greater than $50 \mathrm{~m}$, and up to $90 \mathrm{~m}$ of waste rock placed during operation of the Afton mine. The waste rock was loosely placed. It is generally coarse grained with a variable particle size distribution consisting primarily of sand and gravel with cobbles and boulders, at times with a silt and clay matrix; in contrast, the glacial sediments are heavily overconsolidated and vary from fine-grained glaciolacustrine silt to basal till. The presence of various rock units of variable quality and fabric, steeply dipping faults, irregular (drumlinised) natural topography, and variable thicknesses of overlying waste rockfill have contributed to complex spatial asymmetry in the development of subsidence deformations. 


\section{$2 \quad$ Monitoring objectives and instrument selection}

The subsidence instrumentation network was designed to collect surface and subsurface monitoring data over time to support two primary monitoring objectives:

- Inform the development and calibration of conceptual and numerical models of block cave-induced subsidence.

- Monitor for destabilisation of the ground supporting critical infrastructure.

The meet these objectives, the design needed to consider:

- There is critical infrastructure with limited tolerance for deformation located on the property.

- Bedrock and surficial geology, including historical mine waste rock and glacial deposits with a combined thickness up to $110 \mathrm{~m}$.

- The possible modes of cave-induced subsidence, which include diffuse and concentrated ground deformations.

- The New Afton mine plan - two active cave areas in Lift 1 and potential for additional deeper caves in the future.

Specifically, the monitoring system is designed to identify and characterise movement along bedrock structures and at the boundaries between geological units. It includes surface and subsurface instruments capable of detecting discrete shear and diffuse types of movements.

Subsidence is a progressive process. At a given position, large ground deformations are typically preceded by smaller scale deformation. Monitoring the safety and performance of critical infrastructure as ground deformations propagate outward from the underground mine requires an understanding of the magnitude and progression of the small deformations associated with the continuous subsidence zone and the transition from initial deformation to large magnitude deformations in the fractured zone. The instrumentation system therefore must be able to detect centimetre-scale horizontal and vertical diffuse and discrete (cracking) ground movement at the ground surface.

The instrumentation network must also be dense enough and distributed to characterise spatial variation in ground deformations. Efficient use of limited resources was essential to monitoring success. Simple, low-cost instruments were preferred, e.g. robotic theodolite and prisms, manually surveyed monuments and pin extensometers, time domain reflectometry (TDR) cables, and inclinometers. Complex or expensive instruments were specified as needed in critical areas, including ShapeAccelArrays (SAAs), and multi-point borehole and horizontal extensometers.

The network was designed to detect and characterise changes in ground movement trends over time, to reflect a mining plan that includes multiple extraction areas and anticipated growth of the area impacted by surface subsidence. Instruments were installed in areas of active ground movement and areas where future movements were expected. The frequency of data collection from each instrument type was selected to consider observed and anticipated deformation rates, measurement uncertainty and operational needs.

A summary of the instruments considered and selected is provided in Table 1. 


\section{Table 1 New Afton monitoring system instrumentation selection and design summary}

\begin{tabular}{|c|c|c|c|c|}
\hline & Instrument type & Advantages & Disadvantages & 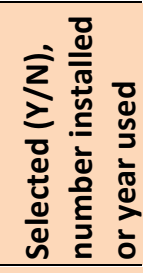 \\
\hline \multirow{5}{*}{ 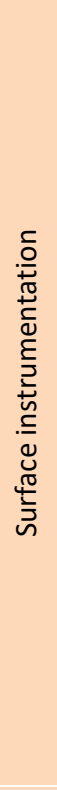 } & $\begin{array}{l}\text { Robotic theodolite and } \\
\text { prisms }\end{array}$ & $\begin{array}{l}\text { Simple, inexpensive, easy to automate, } \\
\text { high accuracy, monitor horizontal and } \\
\text { vertical movement. }\end{array}$ & Requires line of sight. & $Y, 40$ \\
\hline & Survey monuments & $\begin{array}{l}\text { Simple, inexpensive, high accuracy } \\
( \pm 6 \mathrm{~mm}) \text {, monitor horizontal and vertical } \\
\text { movement. Used where robotic } \\
\text { theodolite line of sight obstructed. }\end{array}$ & Manual survey only. & $\mathrm{Y}, 30$ \\
\hline & $\begin{array}{l}\text { Permanent differential } \\
\text { GPS receivers } \\
\text { (e.g. Geocubes) }\end{array}$ & $\begin{array}{l}\text { High accuracy, can be positioned } \\
\text { anywhere, automatic data collection. }\end{array}$ & $\begin{array}{l}\text { Relatively expensive compared to } \\
\text { in-house manual surveying. }\end{array}$ & $\mathrm{N}$ \\
\hline & Pin extensometers & $\begin{array}{l}\text { Simple, inexpensive, high accuracy } \\
\text { ( } \pm 10 \mathrm{~mm} \text { ), provides relative horizontal } \\
\text { and vertical deformation at tension cracks } \\
\text { and manual measurements of crack } \\
\text { aperture, vertical offset, and depth. }\end{array}$ & $\begin{array}{l}\text { Manually read, must be accessible on } \\
\text { ground surface. }\end{array}$ & $\mathrm{Y}, 42$ \\
\hline & $\begin{array}{l}\text { Vibrating wire } \\
\text { extensometers (VWE) }\end{array}$ & $\begin{array}{l}\text { Easy to automate, high accuracy. Easy to } \\
\text { calculate strain. Can monitor deformation } \\
\text { beneath surface infrastructure. }\end{array}$ & $\begin{array}{l}\text { Only provides magnitude of } \\
\text { deformation along instrument. }\end{array}$ & $\mathrm{Y}, 3$ \\
\hline \multirow{3}{*}{ 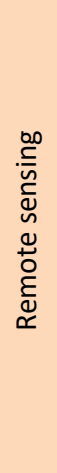 } & $\begin{array}{l}\text { Aerial (drone) } \\
\text { LiDAR }\end{array}$ & $\begin{array}{l}\text { Rapid data collection. Relatively simple } \\
\text { operation and data processing. Can be } \\
\text { very accurate. Can see through } \\
\text { vegetation to 'bare earth'. }\end{array}$ & $\begin{array}{l}\text { Relatively expensive, performed by } \\
\text { subcontractor. No sense for movement } \\
\text { direction, need stable reference points } \\
\text { to confirm data accuracy. }\end{array}$ & $\begin{array}{l}Y, \\
2011- \\
2014\end{array}$ \\
\hline & $\begin{array}{l}\text { Aerial (drone) } \\
\text { photogrammetry }\end{array}$ & $\begin{array}{l}\text { Rapid data collection. Relatively simple } \\
\text { operation. Can be very accurate. Easily } \\
\text { completed by mine staff. }\end{array}$ & $\begin{array}{l}\text { No sense for movement direction, need } \\
\text { stable reference points to confirm data } \\
\text { accuracy. Vegetation can interfere with } \\
\text { topographic surface. Optical method, } \\
\text { requires good visibility. }\end{array}$ & $\begin{array}{l}\text { Y, } \\
\text { 2015- } \\
\text { present }\end{array}$ \\
\hline & InSAR & $\begin{array}{l}\text { Satellite data collected since launch, can } \\
\text { 'see' back in time. }\end{array}$ & $\begin{array}{l}\text { Complex data interpretation, } \\
\text { turnaround time. Relatively expensive. }\end{array}$ & $\mathrm{N}$ \\
\hline \multirow{6}{*}{ 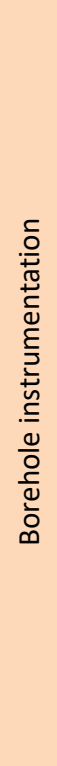 } & Inclinometers & $\begin{array}{l}\text { Simple, inexpensive, high accuracy } \\
\text { ( } \pm 2 \mathrm{~mm} \text { per } 25 \mathrm{~m} \text { ). }\end{array}$ & $\begin{array}{l}\text { Manually read. Short life because } \\
\text { casings cannot tolerate large } \\
\text { movements at discrete shear zones or } \\
\text { large ground settlement (leads to } \\
\text { casing buckling). }\end{array}$ & $Y, 15$ \\
\hline & ShapeAccelArray & $\begin{array}{l}\text { Can tolerate large movements at discrete } \\
\text { shear zones and large ground settlements. } \\
\text { Can be automated (complex). }\end{array}$ & $\begin{array}{l}\text { Complex installation and data } \\
\text { interpretation, expensive. }\end{array}$ & $\mathrm{Y}, 1$ \\
\hline & TDR cables & Simple, inexpensive, easy to automate. & $\begin{array}{l}\text { Indicates areas of ground movement } \\
\text { but not magnitude of movement. }\end{array}$ & $Y, 42$ \\
\hline & $\begin{array}{l}\text { Multi-point borehole } \\
\text { extensometers }\end{array}$ & Simple, easy to automate. & $\begin{array}{l}\text { Expensive, only records deformation in } \\
\text { one dimension along its length. }\end{array}$ & $\begin{array}{l}\mathrm{Y}, \\
2 \text { arrays }\end{array}$ \\
\hline & $\begin{array}{l}\text { Magnetic settlement } \\
\text { datums }\end{array}$ & $\begin{array}{l}\text { Simple, inexpensive, can monitor elevation } \\
\text { change of a specific point in the subsurface. }\end{array}$ & $\begin{array}{l}\text { Manually read. Requires open conduit } \\
\text { to lower reed switch probe. }\end{array}$ & Y, 15 \\
\hline & $\begin{array}{l}\text { Vibrating wire } \\
\text { piezometers }\end{array}$ & Simple, inexpensive, easy to automate. & & $Y, 29$ \\
\hline
\end{tabular}




\section{$3 \quad$ Installation and system set-up}

The instrumentation system to monitor subsidence-induced ground deformations was developed in four main phases between 2011 and 2017. Phasing is advantageous because it allows instruments to be trialled in active areas before committing significant resources to multiple installations and relying on them adjacent to critical infrastructure. The instrumentation in each new phase was designed in consideration of past instrument performance. This section discusses instrument installation and monitoring methods chronologically. Some observational milestones in the development of the subsidence zone at New Afton are also provided as background to the decision-making process. Site-specific challenges and the design solutions used to address them are also discussed.

\subsection{Phase 1}

The first phase of instrumentation was installed between 2011 and 2012 (before to shortly after the initiation of caving). Subsurface instrumentation included TDRs in inclined drillholes and a network of microseismic sensors. These instruments primarily targeted the areas immediately above and around the underground mine to monitor development and propagation of the caved zone toward the ground surface. Surface instrumentation included a network of prisms monitored with a robotic total station which was used to establish baseline ground movement behaviour for comparison with movements related to propagation of the caved zone. Prisms were distributed over a broad area ranging from immediately above the active lift to approximately $450 \mathrm{~m}$ horizontally away from it (Figure 2 ). The caved zone reached the bedrock surface in early 2013, and at approximately the same time, surface subsidence in the form of cracking was observed. New Gold observed the first cracks in May 2013 and began regularly tracking the extent of ground cracking with GPS surveys.

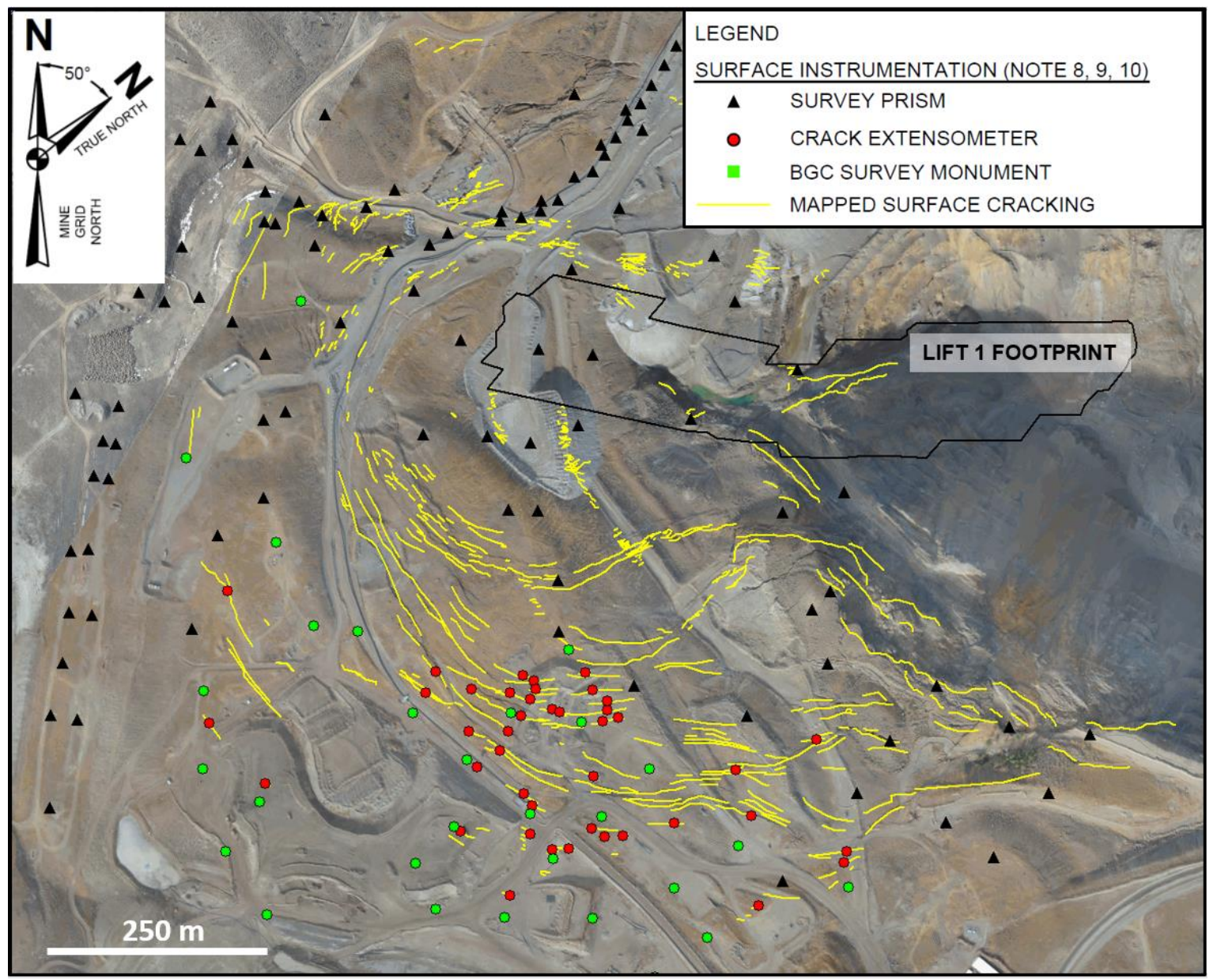

Figure 2 Surface instrumentation and surveyed cracks 


\subsection{Phase 2}

Between 2014 and 2015, the zone of ground movement around the caved zone above the underground lift propagated asymmetrically towards mine grid south. The second phase of instrumentation targeted the developing fractured and continuous subsidence zones around the caved zone that were advancing towards critical surface infrastructure. Five vertical holes were bored for installation of subsurface instrumentation nests (Figure 3). These each contained an inclinometer and one to two piezometers (VWPs); one of the inclinometer holes was twinned to install a magnetic settlement system. VWPs were typically located at the interface between the waste rockfill and native ground surface, and at the bottom of the hole within bedrock. The drillholes were located within and outside the fractured zone and extended 20 to $60 \mathrm{~m}$ into bedrock. The primary purpose of these instruments was to characterise the subsidence behaviour of the overburden units (historical waste rock and glacial till).

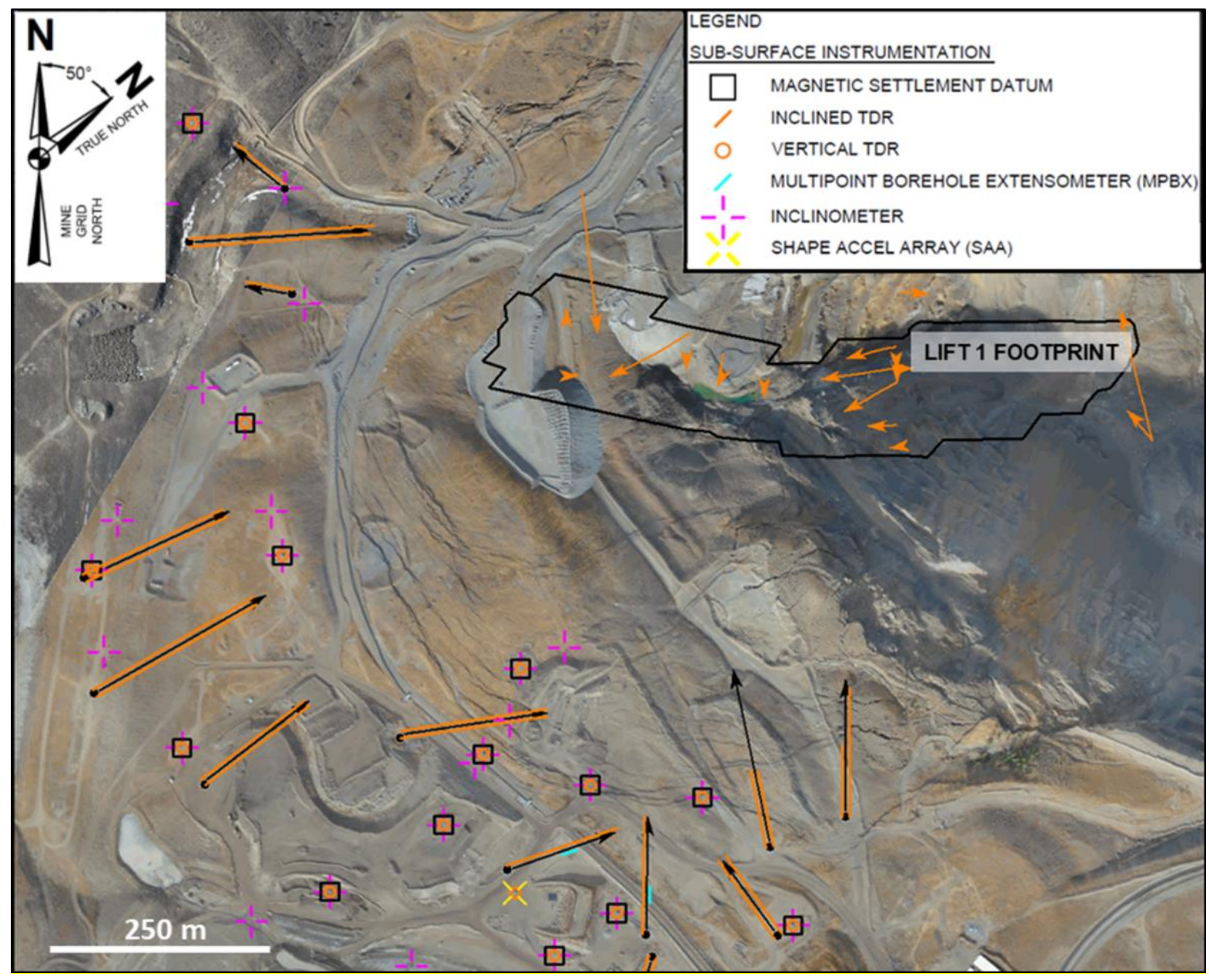

Figure 3 Subsurface deformation monitoring instrumentation

The ground conditions encountered in these boreholes were challenging. Successful installation required a high-quality drilling contractor and engineering support. Both diamond drill coring and reverse circulation methods were used. Advancing through the waste rock hole stability was an issue and establishing fully grouted installations of inclinometer and VWPs in the coarse-grained waste rockfill required significant volumes of grout with curing time between batches. The top 10 to $20 \mathrm{~m}$ could not be grouted and were backfilled with bentonite.

The two installations closest to the underground mine comprised $85 \mathrm{~mm}$ diameter inclinometer casing, as opposed to the standard $70 \mathrm{~mm}$, and were grouted inside the $152 \mathrm{~mm}$ diameter steel casing used during drilling to extend the service life of the instruments given their proximity to the block cave and anticipated magnitude of deformation. 


\subsection{Phase 3}

Between late 2015 and mid-2016, growth of the outer limit of cracking accelerated. By August 2016, three inclinometers installed in mid-2015 were not readable because the casing was too badly deformed. The deformations consisted of a combination of shearing along discrete zones of movement and casing compression leading to buckling.

Phase 3 was implemented mid to late 2016 and included instruments for monitoring surface and subsurface ground movement. The surface monitoring program included:

- Biweekly drone flyovers used to generate photogrammetric topography data. Change detection analysis completed using an average point spacing of $0.4 \mathrm{~m}$.

- Monthly survey and inspection of cracks. The farthest cracks from the centre of subsidence are surveyed using Differential Global Positioning System (DGPS) equipment. Growth of previously identified cracks was surveyed. Pin extensometers were installed across cracks and are surveyed during each field review.

- A total of 30 survey monuments were installed on the ground surface between the underground mine and surface infrastructure. These were to supplement the existing prism network by providing coverage where the line of sight of the robotic theodolite was obstructed. Each monument comprised a concrete lock-block with an attached steel pin and marked survey point.

Subsurface instrument nests were installed in six vertical and seven inclined drillholes between the underground mine and surface infrastructure.

- The vertical holes ranged in depth from 80 to $150 \mathrm{~m}$, extending $50 \mathrm{~m}$ into bedrock. Five of the vertical holes contained an inclinometer, TDR, a magnetic settlement datum and two VWPs. A $85 \mathrm{~mm}$ diameter high-endurance inclinometer casing was used to extend the service life of the instruments. The three installations closest to the caved zone were grouted inside the $152 \mathrm{~mm}$ diameter steel casing (Baker 1991). A ShapeAccelArray was installed in the sixth hole.

- The inclined drillholes were $60^{\circ}$ relative to horizontal and ranged from 200 to $400 \mathrm{~m}$ in length. Four of the holes contained two TDRs, and two contained a TDR and a $35 \mathrm{~m}$ long multi-point borehole extensometer (MPBX) located at the bedrock surface.

\subsection{Phase 4}

Phase 4 was implemented in mid to late 2017 and included instruments for monitoring surface and subsurface ground movement. The surface instrumentation included three horizontal deformation monitoring instrument nests installed near surface infrastructure. Each nest consists of a vibrating wire soil extensometer (VWSE) array and a TDR cable that were installed in trenches dug in the waste rock.

The subsurface instruments included downhole 'instruments nests' installed in five vertical drillholes and one inclined drillhole between the underground mine and surface infrastructure.

- The vertical drillholes were 90 to $160 \mathrm{~m}$ in depth and positioned immediately in front of surface infrastructure that could potentially be impacted by subsidence-induced ground movement. The instrument nests contained an inclinometer, TDR, bedrock magnetic settlement datum and two VWPs installed in the same configuration as the Phase 1 work. Steel casing was not used in these installations, given the lower magnitude of anticipated ground movement at their locations.

- The inclined drillhole was $60^{\circ}$ relative to horizontal and $400 \mathrm{~m}$ long, and contained two TDRs. 


\subsection{Data collection}

Instrument monitoring data is collected either manually or automatically by data loggers depending on instrument type (Table 2). The data collection frequency has been set to suit the needs of the project and is reviewed regularly, and is subject to change. Automated data acquisition is completed using a radio network that delivers data to a server-hosted database.

Table 2 Instrumentation data collection method and frequency

\begin{tabular}{ll}
\hline Instrument type & Data collection method, frequency \\
\hline Survey prisms & Automated, every two hours \\
VWSEs & Automated, every six hours \\
Survey monuments & Manual, monthly \\
Pin extensometers & Manual, monthly \\
VWPs & Automated, every six hours \\
ShapeAccelArray & Automated, every six hours \\
Inclinometers & Manual, every two weeks \\
Magnetic settlement datums & Manual, monthly \\
TDR cables & Automated, every six hours \\
MPBXs & Automated, every six hours \\
\hline
\end{tabular}

\section{$4 \quad$ Monitoring system performance}

\subsection{Surface monitoring}

A comprehensive block cave-induced subsidence deformation monitoring program has been developed that includes a prism and survey monument network, crack surveying, and topographic surveys. Surface point deformation trends are clear, and direction of surface movement can be closely correlated with the areas of active draw. An example of calculated horizontal movement vectors for late 2017 and a plot of cumulative displacement for select survey monuments is provided in Figure 4.

The nature of crack deformation changes is correlated to the total subsidence. The advance of hairline cracks is being closely tracked relative to critical surface infrastructure. Aerial topographic surveys are compared to the baseline survey performed in 2011 to estimate the magnitude and distribution of block cave-induced surface subsidence; the boundary of the area of observed ground cracking roughly correlates to the $1 \mathrm{~m}$ contour of vertical subsidence. 

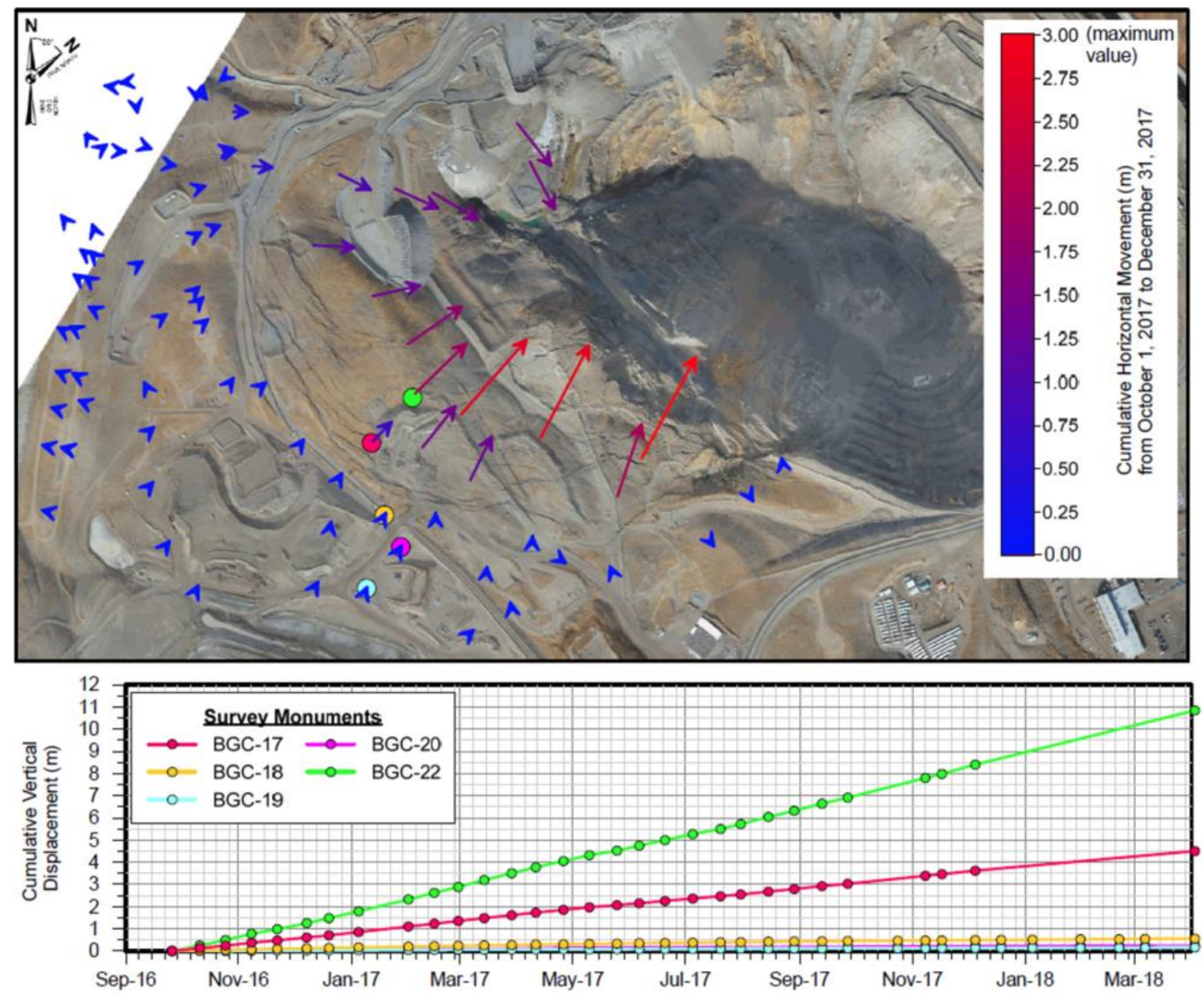

Figure 4 Surface monument monitoring data, direction and magnitude of horizontal displacement during late 2017 indicated in plan; Cumulative vertical displacement in lower graph

\subsection{Inclinometers}

Inclinometers provide profiles of lateral displacement to characterise subsurface ground movements. However, several site-specific challenges were encountered and are discussed below. Figure 5 provides an example of inclinometer data from Phase 2 instruments, illustrating deformation decreasing with distance from the cave, the results of using a surveyed top-reference for the readings, and progressive clipping of the inclinometer casing within the waste rock. 
Closer to Block Caves
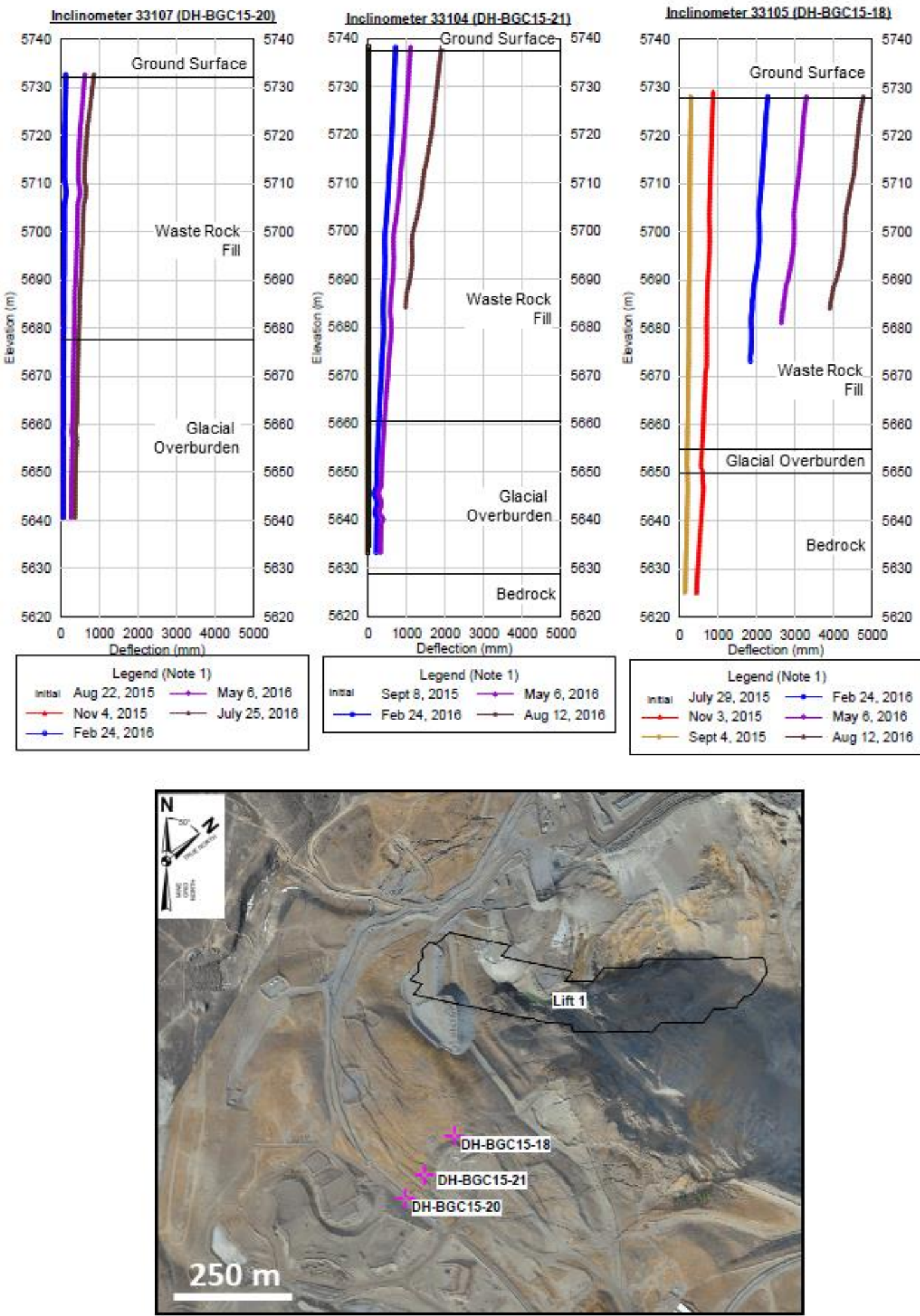

Figure 5 Phase 2 inclinometer data, shown using surveyed top-referencing 


\subsubsection{Considerations for interpretation of data}

Normally, the base of an inclinometer is installed in a stratum known to be stable. In a block cave environment, this is difficult to achieve for conventional installations. To overcome this challenge at New Afton, DGPS surveys of the inclinometer collar are completed with each reading, and the readings are plotted relative to an absolute (surveyed) reference point (Figure 5). At locations where horizontal deformations are small (less than $10 \mathrm{~mm} / \mathrm{month}$ ), conventional (fixed base) data analysis is also completed to check that noise is not being introduced by the DGPS readings that have a $\pm 10 \mathrm{~mm}$ accuracy.

The loose waste rockfill is likely settling because of particle rearrangement stimulated by caving-induced subsidence. The settling fill applies down-drag forces that compress the inclinometer casing into a spiral, which adds noise and potentially depth position errors. When the compression becomes extreme, the casing buckles and is no longer readable below this location. Inclinometers with incomplete grouting have been particularly susceptible. The project has been considering using telescoping casing with an array of casing magnets, but this instrumentation comes with other challenges that is beyond the scope of this paper.

\subsubsection{Failure mechanisms and service life}

Ground deformation has been primarily diffuse (distributed along the casing). To date, most inclinometers have failed due to compression-induced casing buckling. In general, instrument life has decreased with increased ground movement rate (Figure 6). Lifespans of less than two months have been experienced with vertical and resultant ground movement rates greater than $50 \mathrm{~cm} / \mathrm{month}$. Inclinometers have not broken due to shearing in areas with ground movement rates less than $10 \mathrm{~cm} /$ month. Inclinometers in these areas have been operating between eight and 40 months.

Surface displacement between inclinometer installation and failure has typically ranged from 1 to $2 \mathrm{~m}$ in the vertical direction and 1 to $3 \mathrm{~m}$ in the horizontal. Maximum casing curvature at failure has ranged from 5 to $16^{\circ}$. This is consistent with industry experience. Typically, probes begin to have trouble passing 75 and $85 \mathrm{~mm}$ casings with curvature greater than 5 and $7^{\circ}$ respectively.

The combined effect of using steel casing, 85 versus $75 \mathrm{~mm}$ diameter inclinometer casing, and external couplers has increased instrument life. Inclinometer DH-BGC15-20 (no steel, $75 \mathrm{~mm}$ casing, snap and seal joints) became unreadable after 12 months (Figure 5). Replacement inclinometer DH-BGC16-13 (steel, $85 \mathrm{~mm}$ casing, external couplers) is still functioning after 16 months.

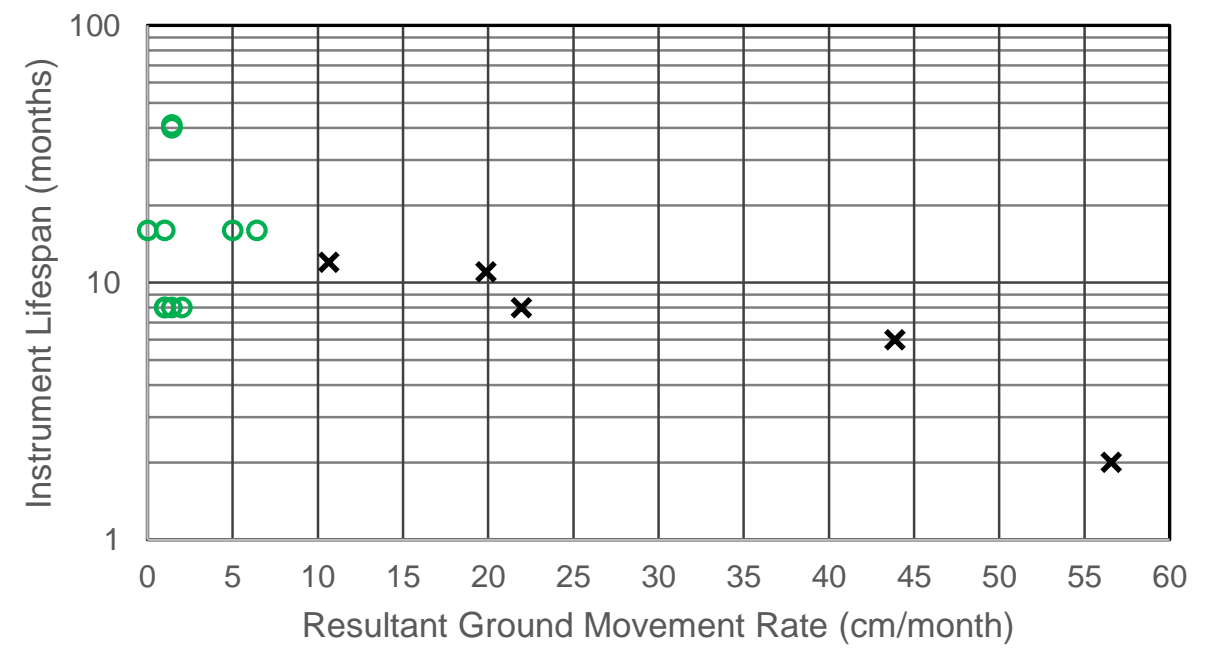

XBroken Inclinometer oOperating Inclinometer

Figure 6 Inclinometer service life relative to ground movement rate 


\subsection{ShareAccelArray}

ShapeAccelArrays are a relatively new geotechnical monitoring tool that can be used to monitor subsurface deformations. SAAs are more complex and expensive than inclinometers but can generally tolerate greater magnitude deformations. Automation of data collection, acquisition and processing is also possible; lateral deformation data can be compared against project quantitative performance objectives (QPOs) in real time and alerts are automatically issued if thresholds are exceeded.

The geotechnical industry continues to learn about factors that influence data interpretation, and there is a small but growing set of published case studies to compare data trends against. An SAA was installed to characterise and monitor subsurface lateral displacement near critical surface infrastructure. The SAA is $120 \mathrm{~m}$ long and was installed in a vertical borehole in December 2016. Overall, the SAA has performed well and provided the data needed to characterise and monitor subsurface ground movements. However, challenges related to SAA rotation were encountered and are the primary focus of this discussion.

The SAA at New Afton includes three magnetometers distributed along its length to monitor rotation around the instrument's longitudinal axis. Instrument rotation is common post-installation for SAAs installed in deep boreholes. This is related to dissipation of residual torsion imparted during the installation process that can cause the SAA to gradually rotate within the borehole over time (Measurand, pers. comm. 2018). Figure 7 shows the change in magnetometer azimuth with time for the SAA installed. The data show that the upper magnetometers (Mag 1 and Mag 2) recorded approximately 2 and $1.5^{\circ}$ of rotation respectively since installation, while the lower magnetometer (Mag 3) recorded negligible rotation. By late September 2017, the azimuth of all three magnetometers had stabilised.

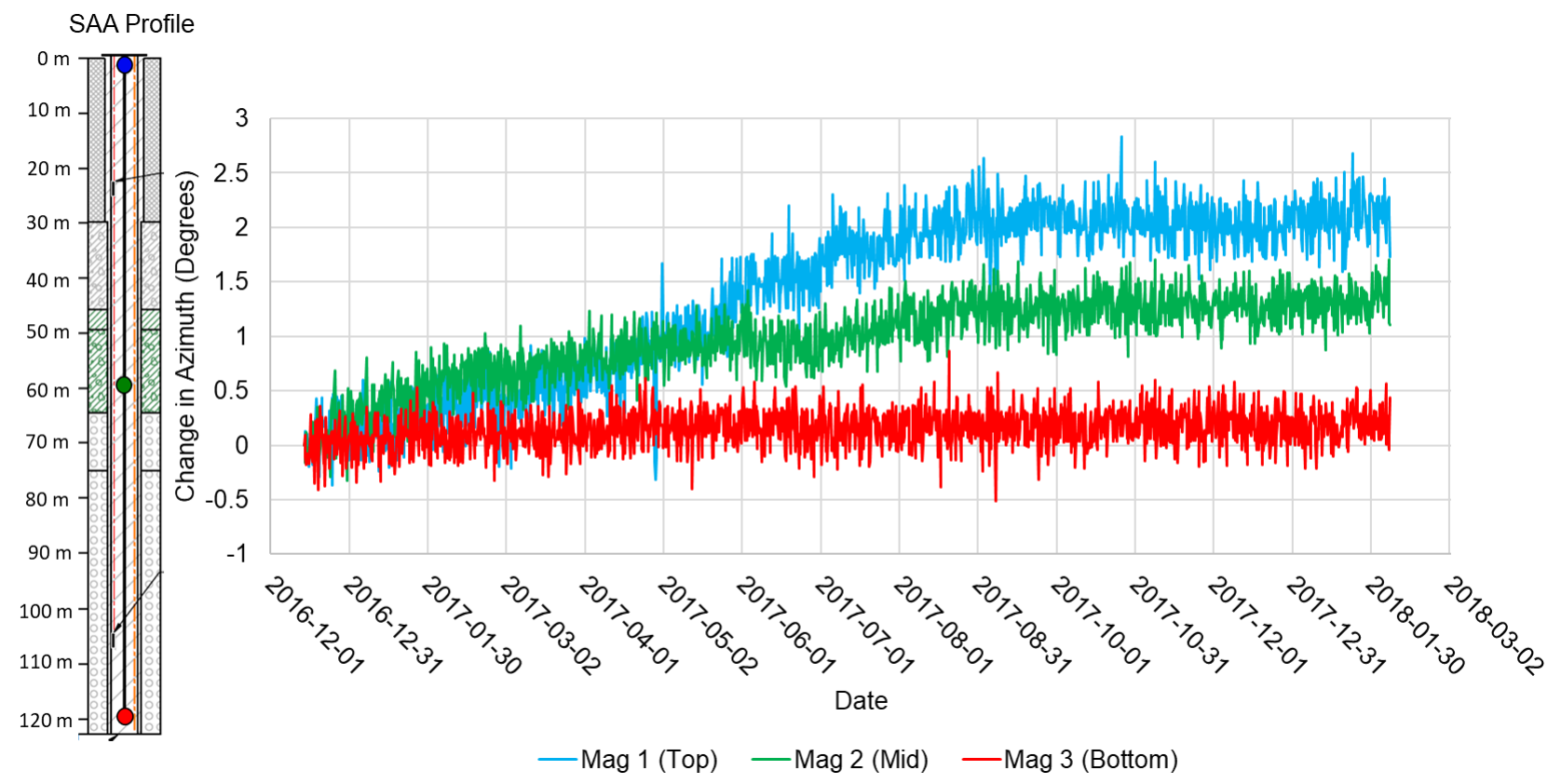

Figure 7 Rotation of magnetometers in the SAA since instrument installation 


\subsubsection{SAA rotation correction}

When the measured raw SAA deformations were reviewed, the estimated magnitude of deformation at the borehole collar was $180 \mathrm{~mm}$ (16 December 2017 to 7 February 2018). GPS collar surveys of the borehole over the same period indicated a horizontal deformation of $95 \mathrm{~mm}$, or approximately $50 \%$ of the SAA-estimated deformation. Surrounding survey monuments confirmed the displacement magnitude from the GPS survey.

The borehole the SAA is installed in plunges at $87.6^{\circ}$, and it was hypothesised that instrument rotation may have caused the overestimate of deformation magnitude. Borehole geometry correction calculations for SAA data processing follow the method described in Mikkelsen (2003). In the case of the SAA at New Afton, the borehole deviates $5 \mathrm{~m}$ in the horizontal direction along its length. If a magnetometer rotation of $2^{\circ}$ is assumed for the entire length of the borehole, there would be an associated measurement error of $175 \mathrm{~mm}$.

Given the observed overestimate of deformation from the raw SAA data, the rotation correction tool in the supplier's software suite was applied. However, this produced an estimated horizontal deformation at the collar of $15 \mathrm{~mm}$, which is $15 \%$ of the GPS collar survey displacement. The interpreted direction of movement was also oriented at $90^{\circ}$ to the observed direction of movement from nearby monuments and of the collar surveys. The standard rotation correction tool failed to adequately decipher rotation-induced deformation from actual ground deformation for several reasons:

- The current rotation correction algorithm uses a constant, fixed rotation correction for all readings. It cannot handle a varying or changing rotation over time, as is seen in the New Afton SAA.

- The trend of the borehole is perpendicular to the anticipated direction of movement and, therefore, the real movements induce rotation of the SAA/magnetometer over time, which makes it difficult for the algorithm to differentiate the real and rotation-induced deformation components.

- Ground deformation at New Afton is not concentrated along discrete shear planes; rather, it is distributed over the entire length of the instrument.

An alternate workflow was developed to more accurately analyse the SAA data at New Afton. The rotation correction tool was not used, and the data was baselined to late September 2017, when the instrument rotation stopped. This involved the following steps:

- The deformation due to rotation between instrument installation and September 2017 when instrument rotation stopped was calculated from the shape of the SAA at that time and the shape of the instrument at installation, referred to as twist correction.

- Subtract the twist correction from the displacement profile of the SAA in September 2017 (which includes real and rotation-induced displacement) to calculate the 'baseline offset profile'.

- Use September 2017 as the baseline for all subsequent readings and calculate cumulative displacements relative to this baseline.

- The baseline offset profile is then added back to the displacements calculated from the September 2017 baseline.

The result of both the standard algorithm correction and baseline approach can be seen in Figure 8 where the pre- and post-processed deformation profiles are compared with the collar surveys. Baselining the data to a period of constant rotation produced the best match between collar movement estimates and surveyed collar coordinates in terms of both magnitude and orientation. 

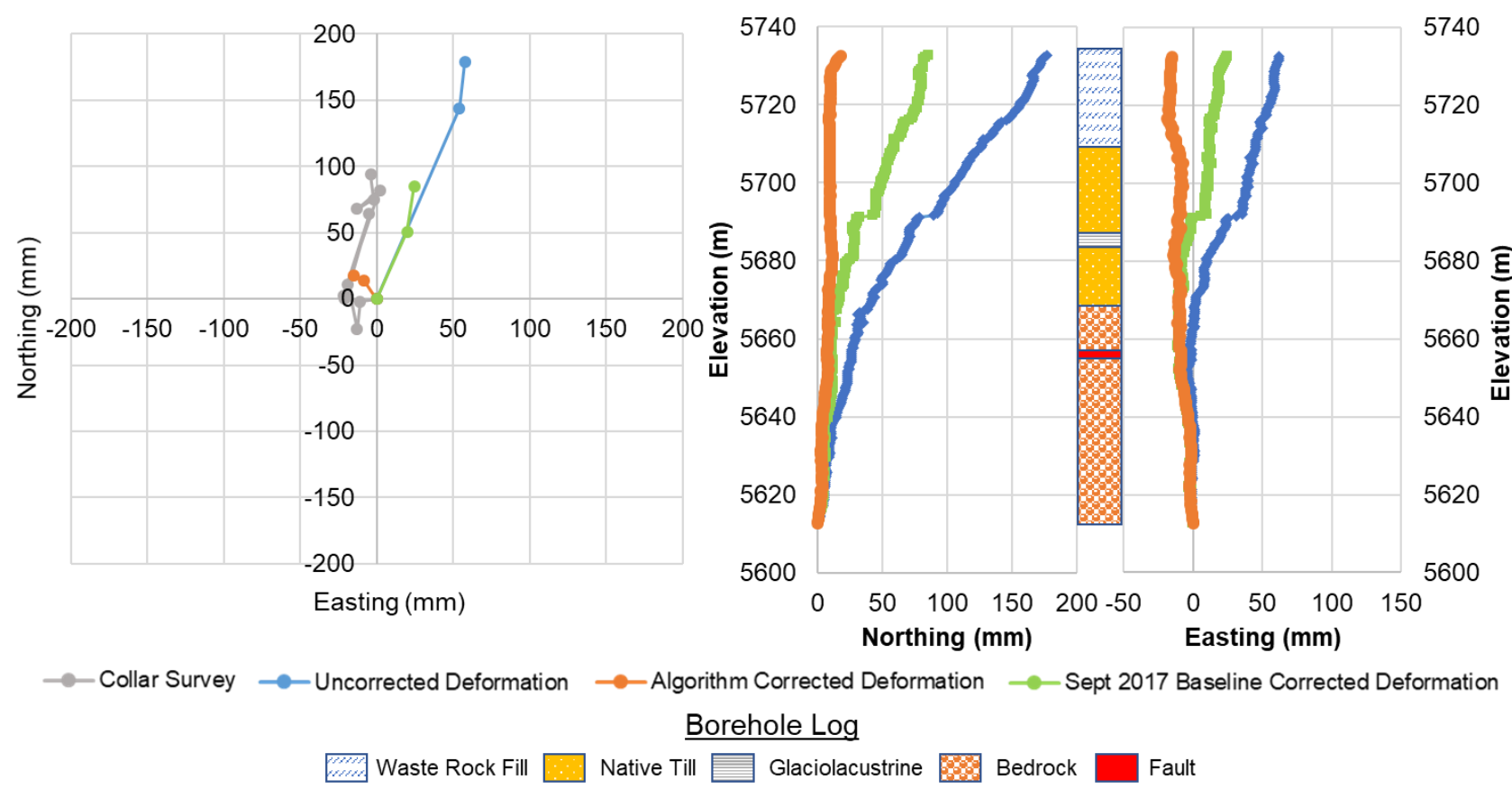

Figure 8 SAA profiles showing; collar movement (left); north-south deformation (centre); and east-west deformation (right) for the 26 January 2018 borehole profile

The same baseline offset profile approach was taken to estimate quarterly deformation of the instrument prior to the end of instrument rotation. Although this does introduce a variable degree of error for each profile $(\sim 4-10 \mathrm{~mm})$, it can give a sense of how the instrument has displaced with time. The result of this approach is shown in Figure 9. It should be noted that the interpreted displacement magnitudes in the east-west fall roughly within the error bounds of the method. This is particularly apparent in the bottom two thirds of the hole where the profiles overlap.

The style and magnitude of deformation in the corrected SAA data agrees with nearby instruments. A discrete zone of movement is observed in the native till at approximately $40 \mathrm{~m}$ below ground surface. A similar trend has been observed in inclinometers in the subsidence zone.

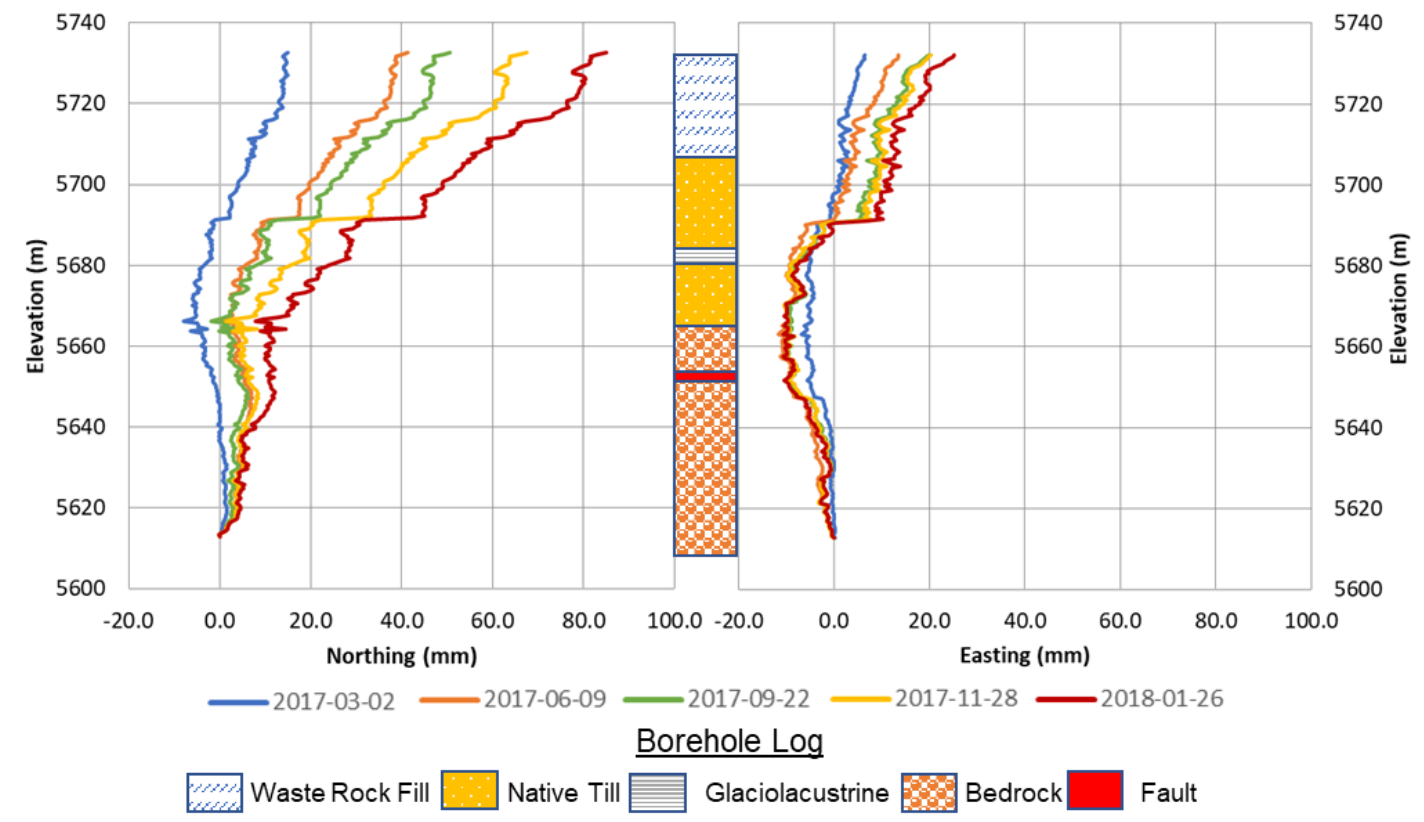

Figure 9 Interpreted displacement profiles of the New Afton SAA at quarterly intervals between March 2017 and January 2018. Borehole stick log units as per Figure 8 


\section{Summary}

The primary goal of developing the comprehensive monitoring program at New Afton was to support investigation of factors controlling subsidence behaviour, development of a conceptual model of future behaviour, and prediction of future subsidence as described in the companion paper (Davies et al. 2018). The phased approach that was taken resulted in a comprehensive instrumentation network that uses simple and inexpensive instruments to characterise large-scale subsidence behaviour, and more complex and expensive instruments to address specific monitoring needs.

Subsurface deformation monitoring at New Afton is not without its challenges, and the lessons learned range from installation practices, data collection and instrument service life through to data processing techniques. For reliable monitoring of subsidence zones, robust instrumentation networks consisting of complimentary instruments, e.g. surface surveying paired with inclinometer readings, or survey prisms and regular topographic surveys, are required. This will allow for development of robust conceptual models of site-specific subsidence mechanisms. The importance of regular data collection is highlighted with respect to instrument functionality and in analysis of behaviour changes.

\section{Acknowledgement}

The writers acknowledge the contribution of a large number of individuals for work reported in this paper, especially the direction and guidance of Clint Logue and Jennifer Brash, among others. We also acknowledge the New Gold staff at the New Afton mine who were instrumental in facilitating the work and operating the monitoring system, including Scott Davidson, Dave Hamilton and Chrystal Simon.

\section{References}

Baker, DG 1991, 'Wahleach power tunnel monitoring', Field Measurements in Geotechnics, A.A. Balkema, Rotterdam, pp. $467-497$.

Davies, A, Hamilton, D \& Clayton, A 2018, 'Understanding and managing surface subsidence at New Gold's New Afton block cave operation', in Y Potvin \& J Jakubec (eds), Proceedings of the Fourth International Symposium on Block and Sublevel Caving, Australian Centre for Geomechanics, Perth, pp. 703-716.

Lipske, J \& Wade, D 2014, Geological Model of the New Afton Copper and Gold Deposit, British Columbia, internal report, New Gold Inc., Vancouver.

Logan, JM \& Mihalynuk, MG 2005, 'Porphyry Cu-Au Deposits of the Iron Mask Batholith, Southeastern British Columbia', Geological Field Work 2004, British Columbia Geological Survey, Vancouver, paper 2005-1.

Mikkelsen, PE 2003, 'Advances in inclinometer data analysis', in F Myrvoll (ed.), Proceedings of the 6th International Symposium on Field Measurements in Geomechanics, CRC Press, Boca Raton, pp. 555-567.

van As, A, Davison, J \& Moss, A 2003, Subsidence Definitions for Block Caving Mines, technical report, Rio Tinto Technical Services. Woo, K 2011, Characterization and Analysis of Discontinuous Subsidence Associated with Block Cave Mining Using Advanced Numerical Modelling and InSAR Deformation Monitoring, The University of British Columbia, Vancouver. 
